Table 1. Mean Numbir of PRIMORdia formed PER Lateral Root SCAR

Month during
which segments
grown
January
June
April

$$
\begin{array}{ccc}
\begin{array}{c}
\text { Time from last } \\
\text { gpray treatment } \\
\text { to excision of } \\
\text { root segment } \\
\text { (weeks) }
\end{array} & \begin{array}{c}
\text { Sprayed 4 times } \\
\text { with water }
\end{array} & \begin{array}{c}
\text { Sprayed 4 times } \\
\text { with gibberellic } \\
\text { acid (Na salt) } \\
1 \text { mg/ml. } \\
\text { in water* }
\end{array} \\
\begin{array}{ccc}
16 & (2) 1.46 \dagger & \text { (6) } 1.59 \pm 0.15 \\
6 & \text { (5) } 1.90 \pm 0.26 & \text { (5) } 1.01 \pm 0.11 \\
2 & \text { (4) } 1.10 \pm 0.26 & \text { (5) } 0.09 \pm 0.04
\end{array}
\end{array}
$$
(5)

$\uparrow$ The standard error is not given where insufficient material was available.

on the nature of the correlation between stem extensiongrowth and regeneration. The main stem has been induced to grow in clonal horseradish plants treated with fortnightly sprays of an aqueous solution of the 75 per cent sodium salt of gibberellic acid. Plants were sprayed four times with $5 \mathrm{ml}$. of the solution, which contains $1 \mathrm{mg}$ of the salt. Control plants were sprayed with the same quantity of distilled water. All seven treated plants olongated, whereas four out of five untreated plants romained as rosettes. Root segments $2 \mathrm{~cm}$ long and $2-5 \mathrm{~mm}$ thick were excised from some of the plants and were grown in the dark at $25^{\circ} \mathrm{C}$ on moist sand in Petri dishes. Segments from troated plants showed different regeneration patterns from the control segments; these results are expressed in Tablo 1 as mean number of primordia formed per lateral root scar. The regeneration pattern appears to be influenced by the length of time between the completion of treatment and the excision of the segments. It is also possible that these differences in root behaviour owe their origin to the use of clonal material of different age or to the different time of year in which experiments wero carried out; seasonality in regenerating horseradish roots has been reported ${ }^{2}$; an age effect is suspected ${ }^{3}$.

Gibberellic acid inhibits root and bud formation when applied directly to Begonia leaf disks ${ }^{4}$, but it inhibits root initiation while promoting root extension-growth in pea and bean stem-cuttings ${ }^{5}$. It has also been reported to inhibit shoot formation in tobacco callus cultures at concentrations which stimulate callus growth ${ }^{6}$. The suggestion has also been made that gibberellic acid enhances the enzymatic destruction of indolyl-3-acetic acid? ${ }^{7}$ In another series of experiments, unpublished results indicate that low concentrations ( 1 p.p.m.) of IAA can diminish the inhibition of root regeneration in treated horsersdish plants. Table 1 indicates an improvement in regeneration ability in treated plants, the longer the interval between treatment and root excision. This would seem to indicate a possible recovery of a regenerationcontrolling system from the inhibitory effect of gibberellic acid. As a working hypothesis, it could be suggested that gibberellic acid pre-treatment in causing extension-growth induces the formation by the elongating stem of either an antagonist to endogenous auxin, or, as seems more probable, the development of an auxin-oxidase mechanism in the roots. It is hoped that investigations in progross on indolyl-3-acetic acid oxidase mechanisms in horseradish will provide additional data which will explain these results.

Department of Biology,

J. DORE

$$
\begin{aligned}
& \text { Brunel College, } \\
& \text { London, W.3. }
\end{aligned}
$$

${ }^{1}$ Dorc, J., and Williams, W. T., Ann. Bot., 20, 231 (1956).

2 Dore, J., Nature, 177, 1189 (1953).

${ }^{3}$ Dore, J., Ph.D. thesis, Univ. Southampton (1954).

"Schraudolf, H., and Reinert, J., Nature, 184, 468 (1959).

' Brian. P. W., Hemming, H. G., and Lowe, D., Ann. Bot., 24, 407 (1960).

- Muraehiga, T., Physiol. Plant., 17, 636 (1964)

'Pjlet, P. E., Physiol. Plant., 14, 787 (1961).

\section{Uptake of Small Particles by Moniliformis dubius (Acanthocephala)}

TyE adults of Monitiformis dubius Meyor livo as parasites in the small intestine of rats. Because they do not possess an alimentary canal, acanthocephalans, like cestodes, must obtain all their food through the surface of
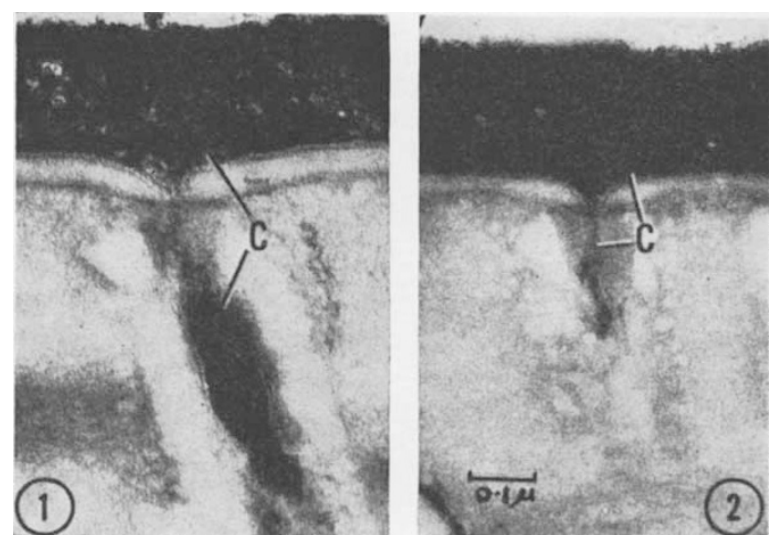

Fig. 1. Transverse section of cuticle of $M$, dubius showing an aggregation of particles of carbon and thorium dioxide within a vesicle below the cuticle (note layer of carbon and thorium dioxide $(C)$ adhering to the outer surface of the cuticle) Fig. 2. Transverse section of cuticle of $M$. dubius showing method of
entry of the carbon and thorium dioxide particles $(C)$

their bodies. It is known that $M$. dubius is ablo to absorb directly through its surface a number of simple sugars ${ }^{1,2}$ and some amino-acids, the latter somotimes against a concentration gradient ${ }^{3,4}$.

Recent oxperiments carried out in this department have shown that $M$. dubius can also take up very small particles of solid matter in a manner that resembles pinocytosis. Figs. 1 and 2 are electronmicrographs of transverse sections of the cuticle of a male of $M$. dubius showing the uptake of a mass of small particles of carbon and thorium dioxide. The worm (aged 7 weeks) after its romoval from the rat was immediately placed in a solution of 0.8 per cent sodium chloride containing carbon particles of diameter about $250 \AA$ aggregating to $500-800 \AA$ and thorium dioxide particles of diameter $70-250 \AA$. The temperature of the solution was maintained at $37^{\circ} \mathrm{C}$. After $3 \mathrm{~h}$ tho worm was removed, washed in warm saline, cut up into small picces, fixed in 2 per cent osmium fixative and embedded in methacrylate. Sections were cut at $600 \AA$.

Confirmatory results showing that the uptake of small carbon particles occurs in vivo were obtained from electronmicrographs of the cuticle of worms removed from rats which had been dosed orally with saline solution containing carbon particles in tho parasite.

We thank Dr. J. R. Casley-Smith, of the Electronmicroscope Unit of the Departments of Botany, Microbiology and Zoology, for his assistance, and Prof. W. P. Roger's for his advice.

S. J. EDMonds

Department of Zoology,

University of Adelaide, South Australia.

${ }^{1}$ Laurie, J. S., Exp. Parasitol., 8, 188 (1959).

"Graff, D. J., J. Parasitol., 50, 230 (1964).

${ }^{3}$ Rothman, A. H., and Fisher, F. M., J. Parasitol, 50, 410 (1964).

‘ Edmonds, S. J., Parasitol., 55, 337 (1965).

\section{Ubiquity of Melanin and the Effect of Phenylthiourea}

BLACK or brown pigments are widespread among animals. Although they have been widely assumed to be melanin, they have not always proved to bo so ${ }^{1}$. Their ubiquity is manifest in another way, by their widespread occurrence in a particular organism.

These pigments have been interpreted as protective, either by assisting concealment ${ }^{2}$ or by acting as a scroen against nocuous radiation ${ }^{3-5}$, and in some cases they have been considered as energy transducers ${ }^{6}$. Such 